\title{
Sistem Pemantauan Temperatur dan Kelembaban Menggunakan Instrumentasi Virtual Sebagai Pendeteksi Dini Bahaya Kebakaran
}

\author{
Hendrianto Husada ${ }^{1}$ \\ ${ }^{1}$ Jurusan Teknik Elektro, Sekolah Tinggi Teknik PLN \\ Email: hendrianto.husada@sttpln.ac.id \\ Samsurizal ${ }^{1}$ \\ ${ }^{1}$ Jurusan Teknik Elektro, Sekolah Tinggi Teknik PLN \\ Email: samsurizal@sttpln.ac.id
}

\begin{abstract}
Virtual instrumentation is a new technology that combines hardware and software computer technology which replace instrument traditional in measurement so that more efficient and accurate. One of the softwares that is used within building a virtual instrumentation is made by National Instrument and called Labview .Combination electronics digital hardware and software labview build an instrument that can do measurement as needed withquite cheap investatment .In this case Laptop and Labview is used to display temperature and Humidity that are captured by arduino system in the display that is easy to see. Wihin this article writer do researching about monitoring temperature and humidity using labview with Arduino system for preventing fire disaster. The sensor used to measure temperature and humidity is DHT11 and the microcontroller used is Arduino Un. The monitoring humidity and tenperature are did at Laboratory of Industrial Electronic STT PLN Jakarta. The results of this study are monitoring temperature and humidity can be done continuously with the Virtual Instrumentation System. Early detection of fire hazard occurs when the temperature change is monitored, the value rises and the humidity value decreases in a very short period of time.
\end{abstract}

Keywordsi : arduino; instrumentasi; labview: temperature: humidity

ABSTRAK.: Instrumentasi virtual adalah suatu teknologi baru yang menggabungkan teknologi perangkat keras dan perangkat lunak komputer menggantikan alat ukur tradisional dalam pengukuran agar lebih efisien dan akurat. Salah satu perangkat lunak yang digunakan dalam membangun suatu instrumentasi virtual adalah perangkat lunak buatan perusahaan National Instrument yang disebut Labview. Penggabungan perangkat keras dan perangkat lunak Labview bisa membentuk alat ukur yang bisa melakukan pengukuran yang sesuai dengan kebutuhan yang diinginkan dengan investasi biaya yang tidak mahal. Dalam hal ini Laptop dengan Labview berfungsi untuk menampilkan hasil penangkapan data temperatur dan kelembaban oleh Sistem Arduino dalam bentuk tampilan yang mudah dilihat. Dalam artikel ini penulis melakukan penelitian mengenai pemantauan temperatur dan kelembaban untuk pencegahan bahaya kebakaran. Sistem tersebut digunakan sebagai pendeteksi dini bahaya kebakaran. Sensor yang digunakan untuk mengukur temperature dan kelembaban udara adalah DHT11 dan mikrokontroler yang digunakan adalah arduino uno. Pemantauan temperatur dan kelembaban dilakukan di Laboratorium Elektronika Industri STT PLN Jakarta. Hasil penelitian ini adalah pemantauan temperatur dan kelembaban dapat dilakukan secara terus menerus dengan Sistem Instrumentasi Virtual. Pendeteksian dini bahaya kebakaran terjadi saat adanya perubahan temperatur yang dipantau nilainya semakin naik dan nilai kelembaban yang semakin turun dalam kurun waktu yang sangat singkat.

Kata kunci : arduino; instrumentasi; labview; temperatur; kelembaban

\section{PENDAHULUAN}

$\mathrm{K}$ emajuan dalam bidang komputer membuat perkembangan aplikasi berbasis komputer berubah cepat sekali. Banyak sistem baru berbasis komputer ditemukan dan digunakan dalam kehidupan sehari-hari seperti handphone, sistem alarm mobil, rumah pintar, mobil pintar dan masih banyak lagi .

Salah satu komponen yang terlibat didalamnya adalah mikrokontroler atau biasa disebut sebagai komputer dalam satu chips. Mikrokontroler yang sangat popular karena sering digunakan sebagai prototype dalam penelitian suatu system elektronik berbasis komputer yang terbaru adalah arduino. Dalam instrumentasi virtual juga demikian, kemajuan teknologi komputer membuat system alat ukur berbasis komputer dikembangkan sebagai pengganti alat ukur tradisional karena adanya perbaikan dalam teknologi , harga dan ketelitiannya.

Dengan menggunakan komputer berikut perangkat lunak dan peralatan elektronik lainnya bisa dibuat suatu sistem baru yang berguna untuk kehidupan sehari-hari. Suatu sistem pemantauan temperatur ruangan dan kelembaban yang digunakan dalam kehidupan sehari-hari bisa dibuat dengan penggunaan laptop dan perangkat lunak Labview serta mikrokontroler arduino berikut perangkat pendukungnya. Sistem tersebut digunakan sebagai pendeteksi dini bahaya kebakaran. Dalam artikel ini penulis menggunakan arduino, sensor, laptop dan perangkat lunak labview untuk melakukan

\footnotetext{
${ }^{1}$ Jurusan Teknik Elektro, Sekolah Tinggi Teknik PLN
} 
pemantauan temperatur ruangan dan kelembaban serta menampilkan hasil pemantauan dengan labview. Dalam hal diatas kondisi temperature dan kelembaban ruangan bisa dilihat langsung secara visual dan jelas dengan menggunakan laptop. Kebakaran adalah suatu bencana yang paling sering terjadi baik di perkotaan maupun di pedesaan. Terutama di daerah yang padat penduduk seperti Jakarta ataupun di kota-kota besar lainnya di Indonesia. Kebakaran merupakan bencana yang berbahaya karena bisa mengakibatkan adanya korban yang meninggal. Disamping itu bisa menimbulkan kerugian material dan biaya yang besar. Untuk mengatasi terjadinya kebakaran penulis melakukan penelitian menggunakan system instrumentasi virtual hasil kombinasi komputer, perangkat lunak labview dan perlengkapan pendukung lainnya seperti arduino. Sistem ini digunakan sebagai pendeteksi dini bahaya kebakaran, dan sebagai tempat penelitiannya di Laboratorium Elektronika Industri STT PLN Jakarta.

\section{A.Blok Diagram}

\section{METODA}

Pada Gambar 1 menunujukkan diagram konfigurasi sistem Instrumentasi Virtual menggunakan labview dan arduino untuk pemantauan temperatur dan kelembaban sebagai pendeteksi dini bahaya kebakaran di ruangan.

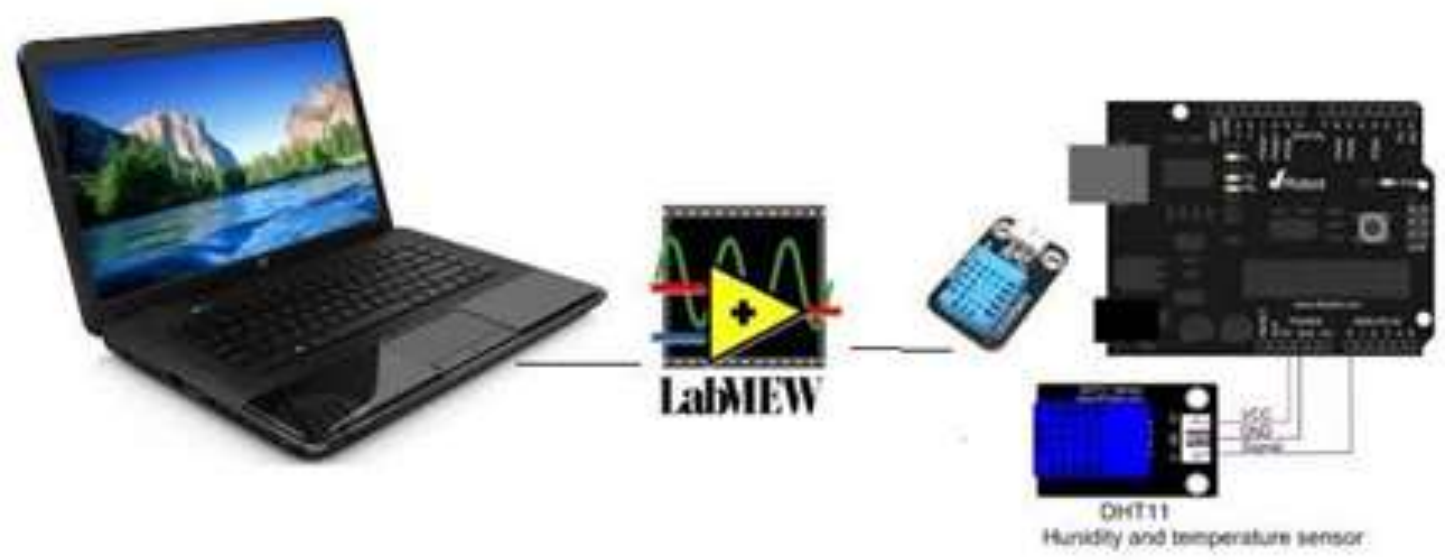

- Gambar1. Diagram Instrumentasi Virtual menggunakan Labview dan Arduino pada PDP 2019

\section{B.Komponen}

\section{Sensor Suhu Dan Kelembaban}

Sensor DHT11 adalah suatu sensor yang digunakan untuk mengukur temperature dan kelembaban udara. Sensor ini, DHT11 termasuk sensor yang memiliki kualitas terbaik, dinilai dari respon, pembacaan data yang cepat, dan kemampuan anti-interference.Ukurannya yang kecil, dan dengan transmisi sinyal hingga 20 meter, membuat produk ini cocok digunakan untuk banyak aplikasi-aplikasi pengukuran suhu dan kelembaban. Pada Gambar 2 dapat dilihat bentuk sensor DHT11

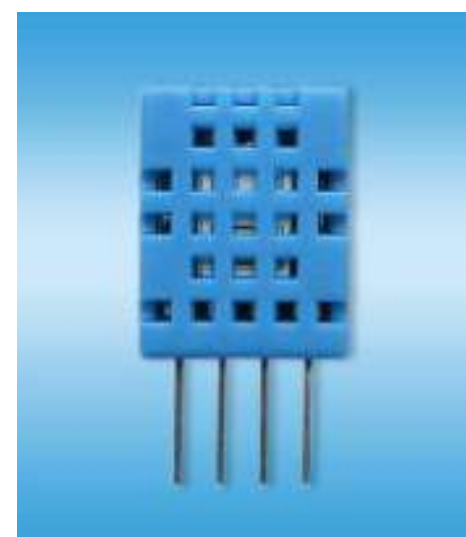

- Gambar 2. Sensor Temperatur dan Kelembaban DHT11 


\section{Arduino Uno}

Arduino Uno adalah board mikrokontroler berbasis ATmega328 (datasheet). Memiliki 14 pin input dari output digital dimana 6 pin input tersebut dapat digunakan sebagai output PWM dan 6 pin input analog, $16 \mathrm{MHz}$ osilator kristal, koneksi USB, jack power, ICSP header dan tombol reset. Untuk mendukung mikrokontroler agar dapat digunakan, cukup hanya menghubungkan Board Arduino Uno ke komputer dengan menggunakan kabel USB atau listrik AC ke adaptor-DC atau baterai untuk menjalankannya. Adaptor ini dapat dihubungkan dengan menancapkan plug jack pusat- positif ukuran $2.1 \mathrm{~mm}$ konektor $P O W E R$. Ujung kepala dari baterai dapat dimasukkan kedalam Gnd dan Vin pin header dari konektor POWER. Kisaran kebutuhan daya yang disarankan untuk board Uno adalah7 sampai dengan 12 Volt, jika diberi daya kurang dari 7 Volt kemungkinan pin 5Volt Uno dapat beroperasi tetapi tidak stabil kemudian jika diberi daya lebih dari $12 \mathrm{Volt}$, regulator tegangan bisa panas dan dapat merusak board Uno.

Uno berbeda dengan semua board sebelumnya dalam hal koneksi USB-to-serial yaitu menggunakan fitur Atmega8U2 yang diprogram sebagai konverter USB-to-serial berbeda dengan board sebelumnya yang menggunakan chip FTDI driver USB-to- serial.

Masing-masing dari 14 pin digital di Uno dapat digunakan sebagai input atau output, dengan menggunakan fungsi pinMode (), digitalWrite (), dan digitalRead (), beroperasi dengan daya 5 Volt. Setiap pin dapat memberikan atau menerima maksimum $40 \mathrm{~mA}$ dan memiliki internal pull-up resistor (secara default terputus) dari $20-50 \mathrm{k} \Omega$.

Arduino Uno memiliki sejumlah fasilitas untuk berkomunikasi dengan komputer, Arduino lain, atau mikrokontroler lainnya. ATmega328 menyediakan UART TTL (5V). Untuk komunikasi serial, yang tersedia di pin digital 0 (RX) dan 1 (TX). Sebuah ATmega8U2 sebagai saluran komunikasi serial melalui USB dan sebagai port virtual com untuk perangkat lunak pada komputer. Perangkat lunak Arduino terdapat monitor serial yang memungkinkan digunakan memonitor data tekstual sederhana yang akan dikirim ke atau dari board Arduino. LED RX dan TX di papan tulis akan berkedip ketika data sedang dikirim melalui chip USB-to-serial dengan koneksi USB ke komputer (tetapi tidak untuk komunikasi serial pada pin 0 dan 1)

Arduino Ide

Software arduino yang digunakan adalah driver dan IDE, walaupun masih ada beberapa software lain yang sangat berguna selama pengembangan arduino. Integrated Development Environment (IDE), suatu program khusus untuk suatu komputer agar dapat membuat suatu rancangan atau sketsa program untuk papan Arduino. IDE arduino merupakan software yang sangat canggih ditulis dengan menggunakan java.IDE arduino terdiri dari:

\section{Editor Program}

Sebuah window yang memungkinkan pengguna menulis dan mengedit program dalam bahasa pemrosesan.

2. Compiler

Berfungsi untuk kompilasi sketchtanpa unggah ke board bisa dipakai untuk ngecekan kesalahankode sintaks sketch. Sebuah modul yang mengubah kode program menjadi kode biner bagaimanapun sebuah mikrokontroler tidak akan bisa memahami bahasa pemrosesan.

3. Uploader

Berfungsi untuk mengunggah hasil kompilasi sketch ke board target. Pesan error akan terlihat jika board belum terpasang atau alamat port COM belum terkonfigurasi dengan benar. Sebuah modul yang memuat kode biner dari computer kedalam memory didalam papana rduino.(Sumber:B.Gustomo, 2015).Tampilan arduino ide dapat dilihat pada Gambar 3. 


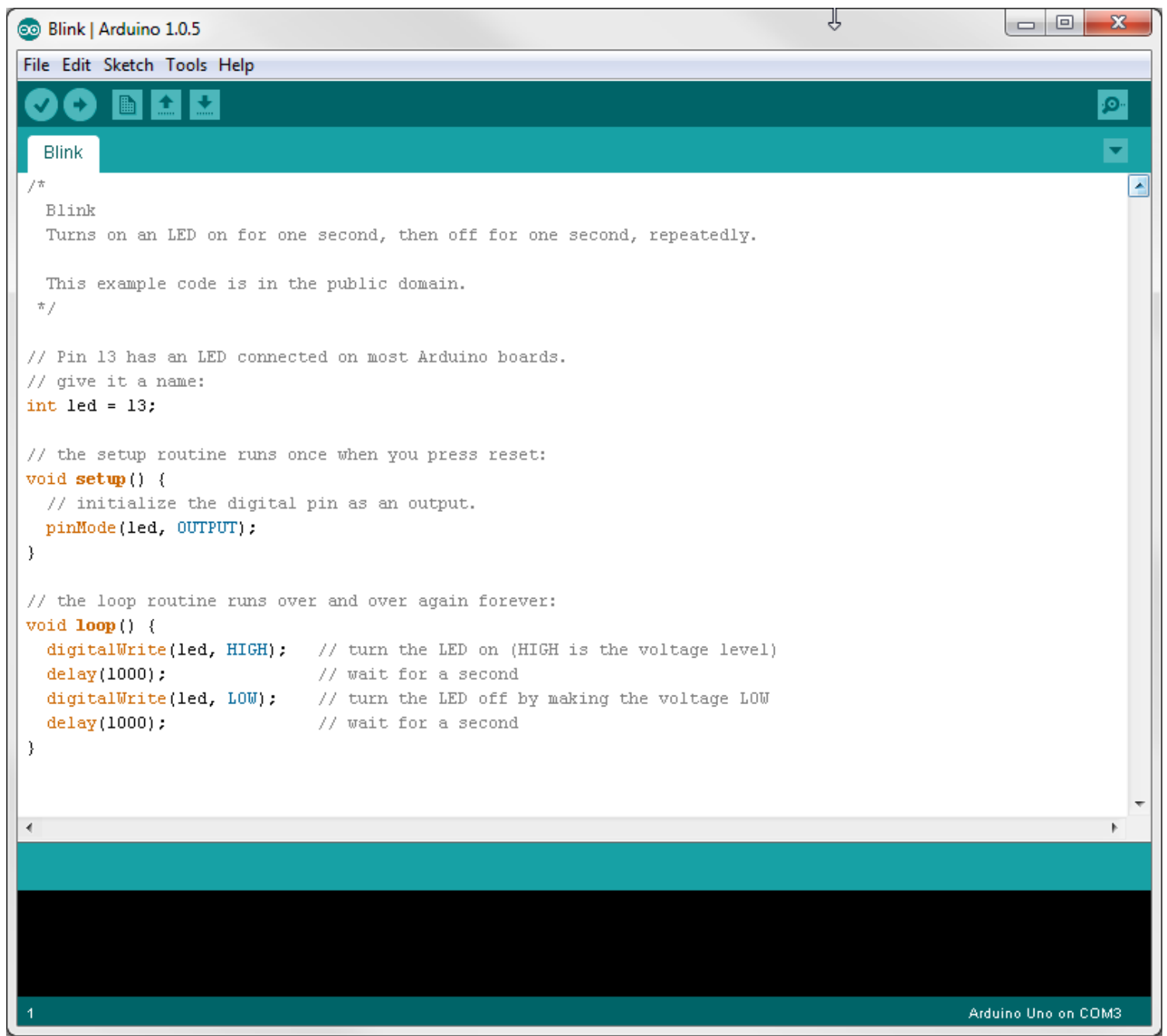

- Gambar 3. Tampilan perangkat lunak arduino ide

\section{LABVIEW}

LabVIEW merupakan sebuah software pemograman yang diproduksi oleh National instruments dengan konsep yang berbeda. Seperti bahasa pemograman lainnya yaitu $\mathrm{C}++$, matlab atau Visual basic ,LabVIEW juga mempunyai fungsi dan peranan yang sama, perbedaannya bahwa labVIEW menggunakan bahasa pemrograman berbasis grafis atau blok diagram sementara bahasa pemrograman lainnya menggunakan basis text. Program labVIEW dikenal dengan sebutan Vi atau Virtual instruments karena penampilan dan operasinya dapat meniru sebuah instrument. Pada labVIEW, user pertama-tama membuat user interface atau front panel dengan menggunakan control dan indikator, yang dimaksud dengan kontrol adalah knobs, push buttons, dials dan peralatan input lainnya sedangkan yang dimaksud dengan indikator adalah graphs, LEDs dan peralatan display lainnya. Setelah menyusun user interface, lalu user menyusun blok diagram yang berisi kode-kode VIs untuk mengontrol front panel. Software LabVIEW terdiri dari tiga komponen,yaitu :

1. Front panel front panel adalah bagian window yang berlatar belakang abu-abu serta mengandung control dan indikator. front panel digunakan untuk membangun sebuah VI, menjalankan program dan mendebug program. Tampilan dari front panel dapat di lihat pada Gambar 4. 


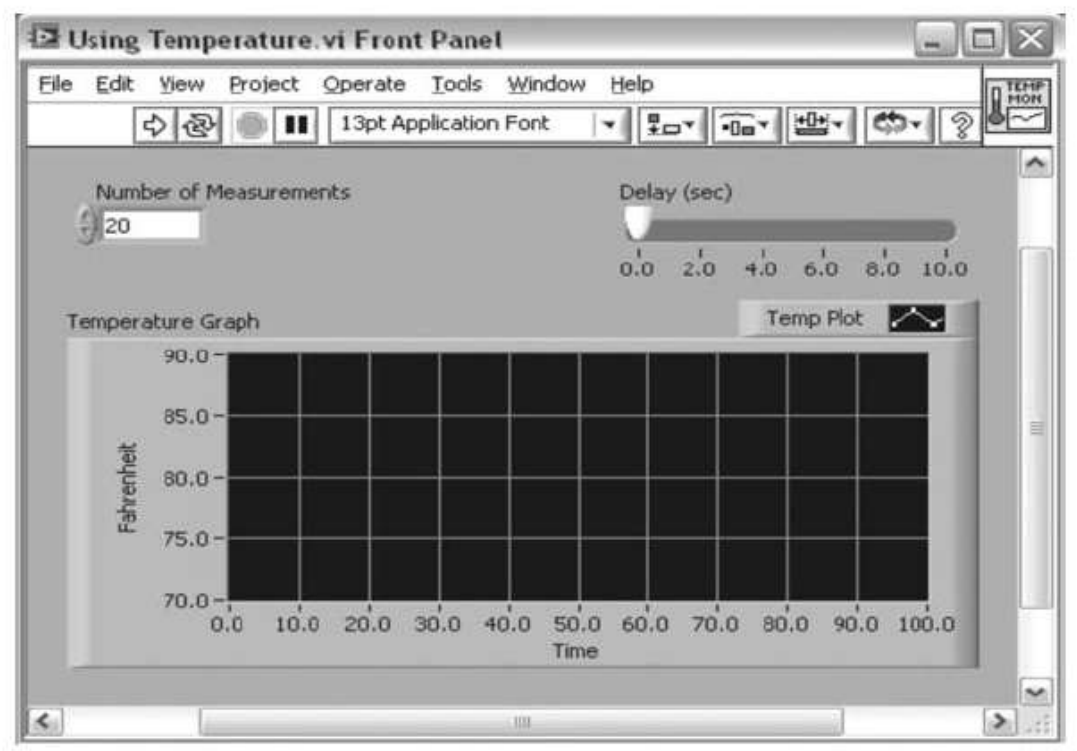

- Gambar 4. Front Panel

2. Blok diagram dari Vi Blok diagram adalah bagian window yang berlatar belakang putih berisi source code yang dibuat dan berfungsi sebagai instruksi untuk front panel. Tampilan dari blok diagram dapat lihat pada Gambar 5.

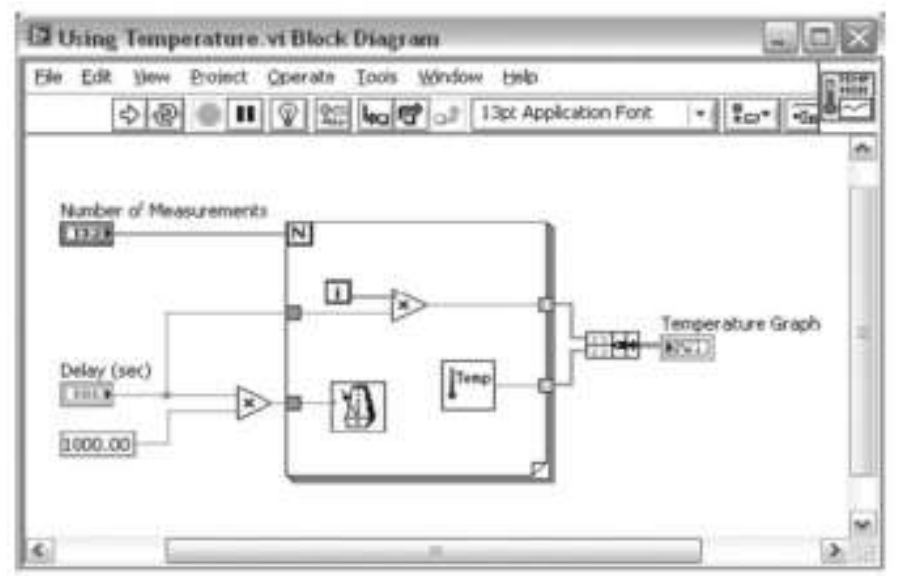

- Gambar 5. Blok Diagram

3. Control dan Functions PalleteControl dan Functions Pallete digunakan untuk membangun sebuah Vi. a.Control Pallete Control Pallete merupakan tempat beberapa control dan indikator pada front panel, control pallete hanya tersedia di front panel, untuk menampilkan control pallete dapat dilakukan dengan mengkilk windows >> showcontrol pallete atau klik kanan pada front panel. Contoh control pallete ditunjukkan pada Gambar 6. 


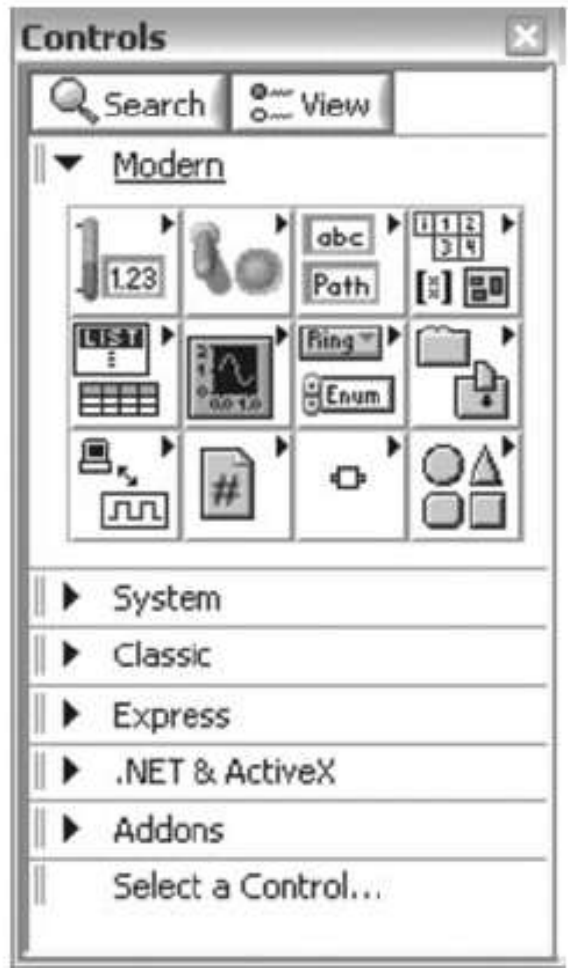

- Gambar 6. Control Pallet

4. Functions Pallete Functions Pallete di gunakan untuk membangun sebuah blok diagram, functions pallete hanya tersedia pada blok diagram, untuk menampilkannya dapat dilakukan dengan mengklik windows > show control palleteatau klik kanan pada lembar kerja blok diagram. Contoh dari functions pallete ditunjukkan Gambar7.

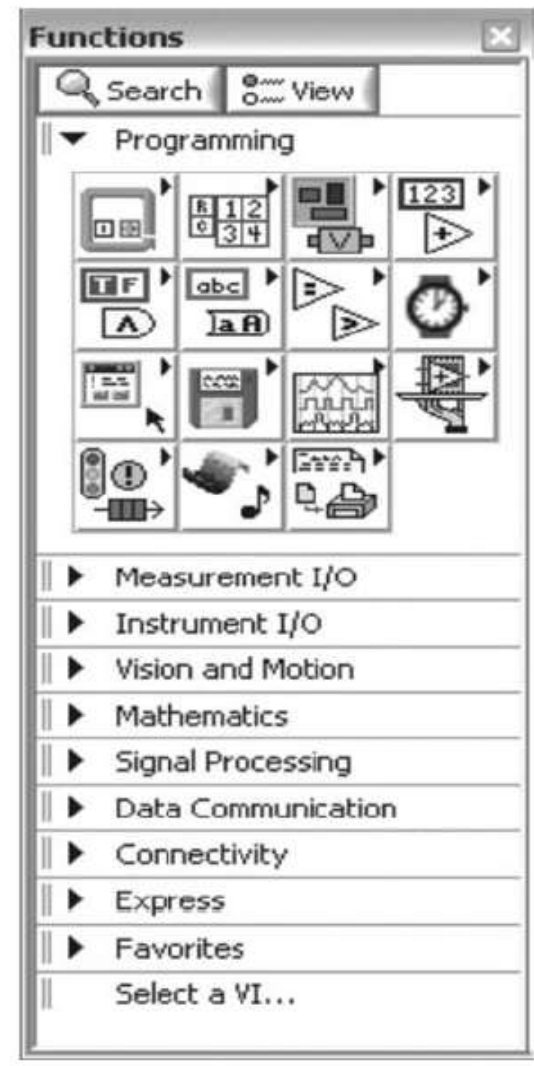

- Gambar 7. Function Pallete 
C.Diagram alir Prosedur Pelaksanaan Penelitian

Pada Gambar 8 menunjukkan diagram alir proses penelitian yang dilakukan

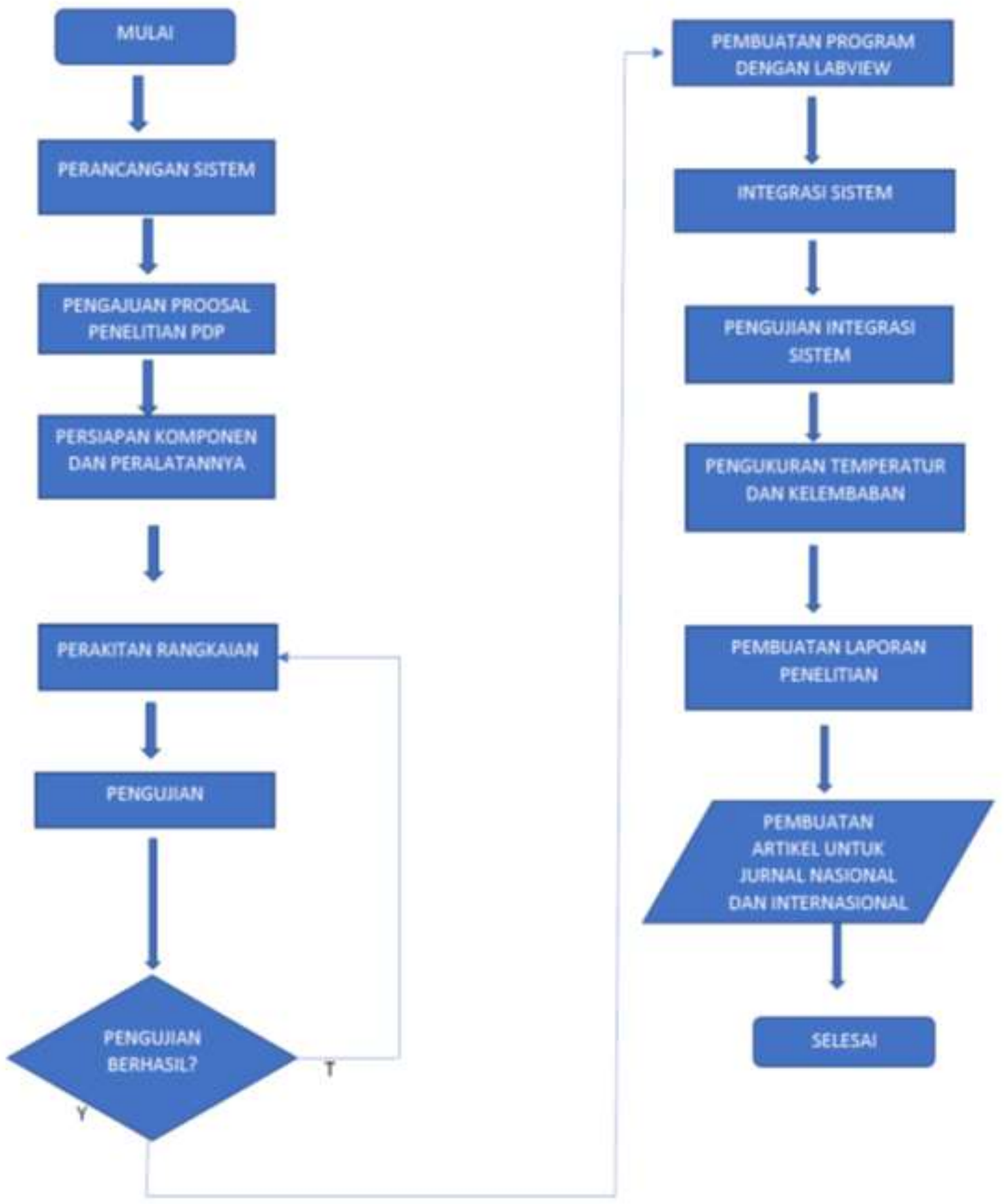

ש Gambar 8 Diagram alir Proses Penelitian Dosen Pemula 2019 
D. Diagram alir Prosedur Pendeteksian Dini Bahaya Kebakaran

Pada Gambar 9 menunjukkan diagram alir pendeteksian dini bahaya kebakaran

Di lokasi sensor DHT11 dipasang.

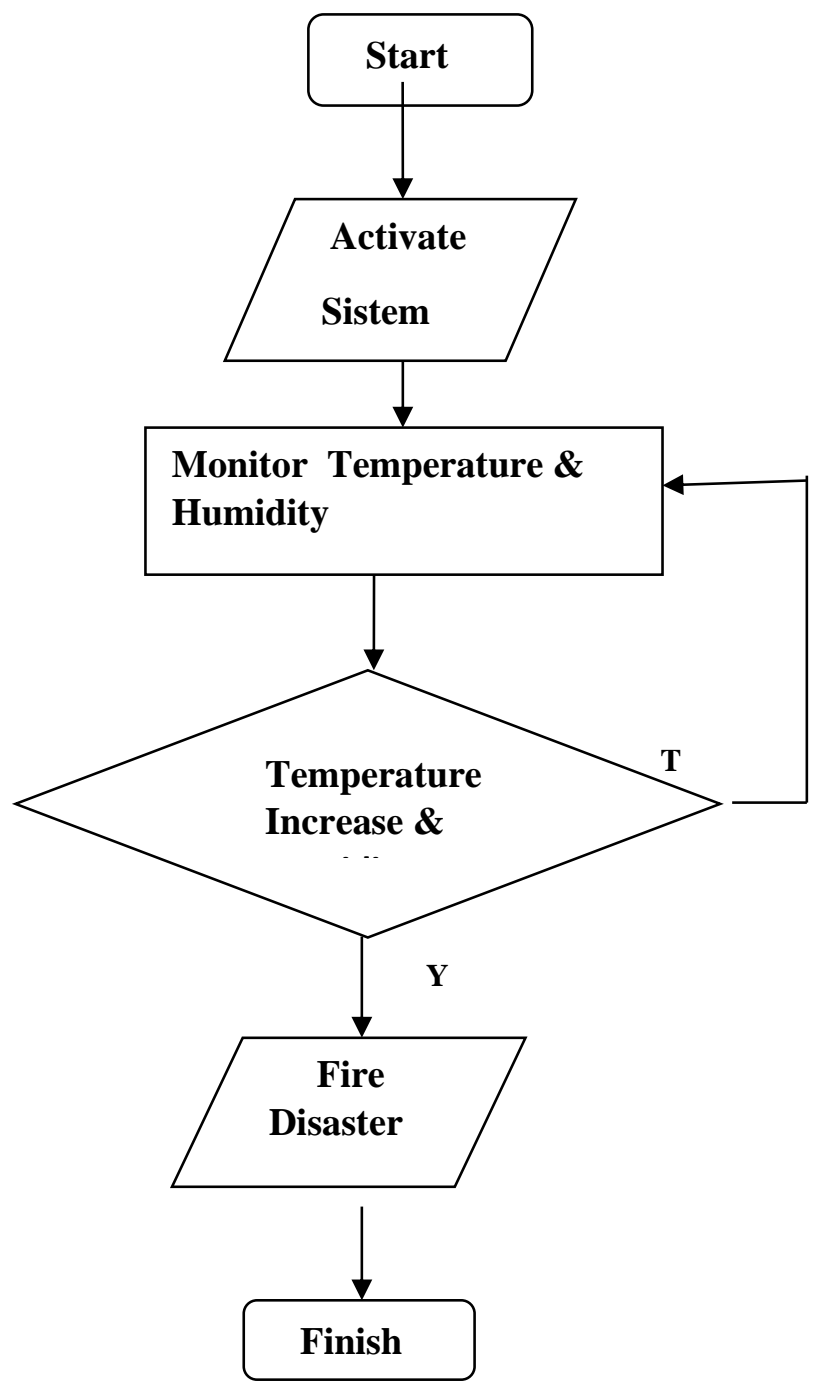

- Gambar 9. Diagram alir Proses Pendeteksian Dini Bahaya Kebakaran

HASIL DAN PEMBAHASAN

1.Pengujian Sensor Suhu dan Kelembaban

Pada Gambar 10 menunjukkan Pengujian Pengukuran untuk suhu dan kelembaban

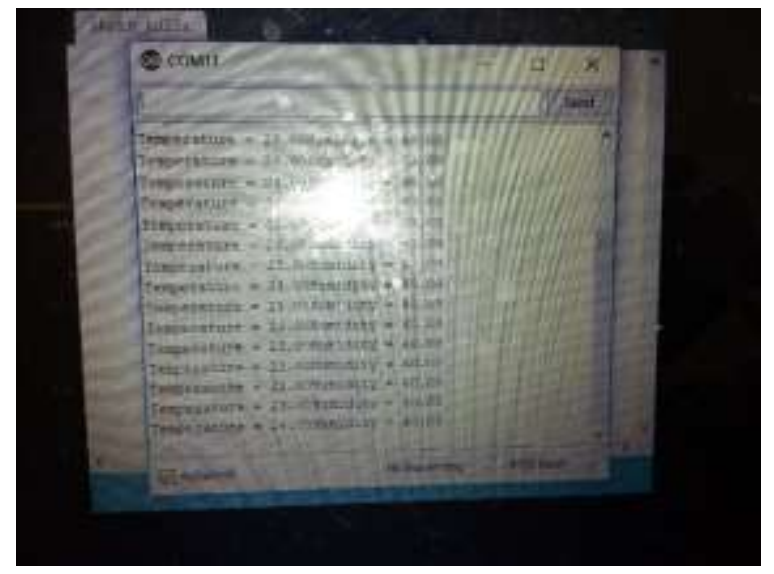

- Gambar 10. Foto Pengujian Pengukuran Suhu dan Kelembaban 
2.Pengujian Integrasi Sistem Dalam Kondisi menggunakan Oven

Langkah-langkah pengujian:

1.Sistem dimasukkan dalam oven,kemudian diukur temperature dan kelembabannya

2.Oven diaktifkan ,temperature dan kelembabannya diukur setiap 5 detik hingga

Temperature mencapai $49^{\circ} \mathrm{C}$

3.Setelah temperature mencapai $50^{\circ} \mathrm{C}$ oven di non aktifkan

Pada Gambar 11 dapat dilihat hasil tampilan pantauan temperature dan kelembaban menggunakan labview.

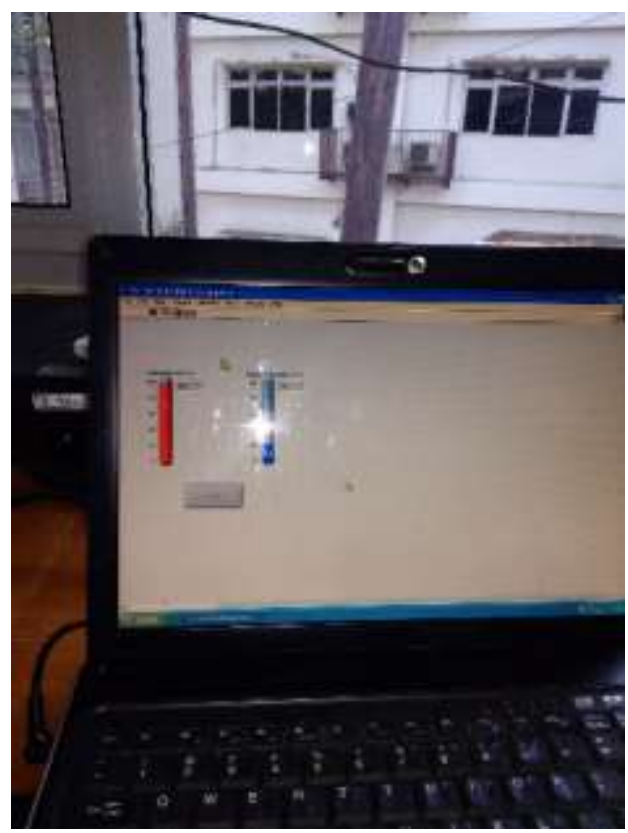

- Gambar 11. Tampilan Temperatur dan Kelembaban menggunakan Labview

3. Pembuatan Tabel Suhu dan Kelembaban

Data -data temperature dan kelembaban yang direkam di Laboratorium. Elektronika Industri Pada Hari Jum'at, 6 September 2019, Pk 12:00 - Pk 12:30 dapat dilihat pada Tabel 1.

- Tabel 1.Temperatur dan Kelembaban

\begin{tabular}{|c|c|c|c|l|}
\hline No & Waktu & Temperatur [o C] & Kelembaban [\%] & Keterangan \\
\hline & & & & \\
\hline 1 & $12: 00$ & 30 & 33 & \\
2 & $12: 05$ & 32 & 32 & \\
3 & $12: 10$ & 34 & 30 & \\
4 & $12: 15$ & 39 & 26 & \\
5 & $12: 20$ & 41 & 25 & \\
6 & $12: 25$ & 43 & 24 & \\
7 & $12: 30$ & 49 & 21 & \\
\hline
\end{tabular}


4.Grafik Hubungan Temperatur dan Kelembaban saat temperature berubah dari normal hingga $49^{\circ} \mathrm{C}$

Pada gambar 12 dapat dilihat grafik hubungan antara temperature dan kelembaban, dimana sumbu x Untuk temperature dan sumbu y untuk kelembaban
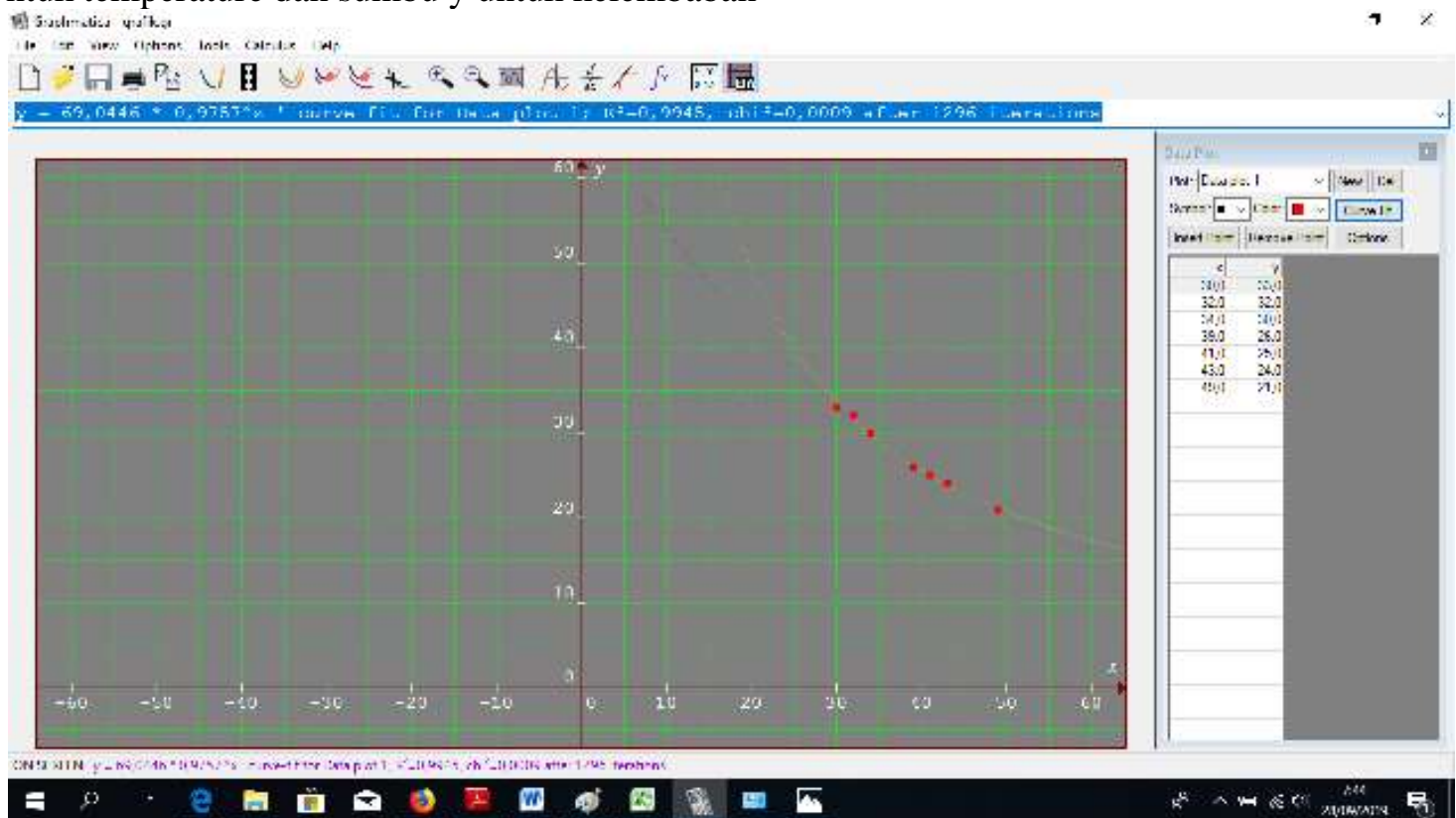

- Gambar 12. Grafik hubungan antara tempertur dan kelembaban

\section{KESIMPULAN}

Pemantauan Temperatur dan kelembaban.dapat dilakukan secara terus menerus dengan Sistem Instrumentasi Virtual. Hasil pantauan digunakan untuk mengetahui kondisi lingkungan laboratorium Elektronika Industri STT PLN Jakarta. Pendeteksian dini bahaya kebakaran terjadi saat adanya perubahan temperatur yang dipantau nilainya semakin naik dan nilai kelembaban yang semakin turun dalam kurun waktu yang sangat singkat.

\section{DAFTAR PUSTAKA}

[1]. Wolf, Stanley -Smith Richard. F.M, Student Reference Manual for Electronic Instrumentation Laboratories, Second Editin, 2004 Pearson Education. Inc

[2]. Clark, Cory L. LABVIEW Digital Signal Processing and Digital Communication,2005, Mc Graw- Hill.

[3]. Scwartz,Marco, and Manickum, oliver, Programming Arduino with Labview, 2015, Packt Publishing, Birmingham, Mumbai,UK

[4]. Jerome, Jovitha, Virtual Instrumentation Using Labview,2010,PHI Learning Private Limited, New Delhi

[5]. AOSONG, Temperature and Humidity DHT11 Product Manual www.theengineeringproject.com.[26 okt 2019] 